\title{
Population status and distribution modelling of the critically endangered Riverine Rabbit (Bunolagus monticularis).
}

\author{
Kai Collins ${ }^{1^{*}}$ \\ ${ }^{1}$ Mammal Research Institute, Department of Zoology \& Entomology, University of Pretoria, Pretoria, 0002, South \\ Africa
}

*Correspondence: E-mail: kcollins@zoology.up.ac.za

\begin{abstract}
The Riverine Rabbit (Bunolagus monticularis), a habitat specialist, is one of the most endangered mammals in southern Africa due to the large-scale fragmentation of Karoo riverine vegetation in South Africa that it inhabits. B. monticularis is an important indicator of ecosystem health and an umbrella species for conservation of the unique riverine ecosystems of the Karoo and the important ecological processes they maintain. This study aimed to contribute towards our understanding of $B$. monticularis through an assessment of historical survey data to better understand population status and distribution.

Geospatial analysis using GIS and distribution modelling was done using Maxent. Extent of occurrence for the species is $54,227 \mathrm{~km}^{2}$ and area of occupancy $2,943 \mathrm{~km}^{2}$. Population size estimates of between 157 and 207 mature individuals indicate extremely low population size for $B$. monticularis and along with the estimate that no subpopulation contains more than 50 mature individuals, supports the species' continued listing as Critically Endangered under IUCN Red List criteria C2a(i). Maxent models performed well in terms of predictive ability and fit and continue to be a useful tool for assessing potential future conservation and management actions for this species.
\end{abstract}

Key Words:

Riverine rabbit, species distribution, population modelling, habitat suitability models, critically endangered

\section{Introduction}

The riverine rabbit, Bunolagus monticularis, is on the verge of extinction and is listed as Critically Endangered under IUCN red list criterion C2a(i). A small population size of less than 250 mature individuals and no subpopulations containing more than 50 mature individuals (Collins et al., 2003) led to this initial listing (although it is based on very limited data). The species is endemic to South Africa's Karoo region and is separated into a northern and southern population, each consisting of several smaller subpopulations 
(Table 1). Until very recently, none of the species' known range occurred on formally protected land (Ahlmann et al., 2000), however an additional southern subpopulation was recently discovered in Anysberg Nature Reserve and portions of the northern population's range are informally protected within Riverine Rabbit Conservancies.

Table 1 List of subpopulations showing total sightings, sightings with duplicates removed, number of estimated mature individuals as well as sightings per area of $1 \mathrm{~km}$ river buffer (see main text) and resultant estimate of population density per subpopulation.

\begin{tabular}{|c|c|c|c|c|c|c|c|}
\hline No. & River & $\begin{array}{l}\text { Total } \\
\text { sightings }\end{array}$ & $\begin{array}{l}\text { Sightings no } \\
\text { duplicates*- }\end{array}$ & $\begin{array}{l}\text { Mature } \\
\text { Individuals*t** }\end{array}$ & $\begin{array}{l}\text { Area of } 1 \mathrm{~km} \\
\text { river buffer }\end{array}$ & $\begin{array}{l}\text { Sightings per } \\
\mathrm{km} 2 \text { buffer }\end{array}$ & $\begin{array}{l}\text { Population } \\
\text { density }\end{array}$ \\
\hline S1 & Touws river & 60 & 39 & 27 & 256 & 0.15 & High \\
\hline S2 & Bree river \& Touws river & 16 & 13 & 9 & 139 & 0.09 & Medium \\
\hline $\mathbf{S 3}$ & Brak river \& Touws river & 22 & 22 & 15 & 119 & 0.18 & High \\
\hline N4 & Riet river & 13 & 13 & 9 & 239 & 0.05 & Low \\
\hline N5 & Klein Riet river & 38 & 35 & 25 & 338 & 0.10 & Medium \\
\hline N6 & Sout river (West) \& Sak River & 14 & 12 & 8 & 106 & 0.11 & Medium \\
\hline N7 & Sak River & 104 & 66 & 46 & 593 & 0.11 & Medium \\
\hline N8 & Bloemfontein River \& Sak River & 22 & 22 & 15 & 111 & 0.20 & High \\
\hline N9 & Brak river & 15 & 13 & 9 & 209 & 0.06 & Low \\
\hline N10 & Krom river & 25 & 20 & 14 & 132 & 0.15 & High \\
\hline N11 & Klein-Brak river \& Groen river & 24 & 19 & 13 & 361 & 0.05 & Low \\
\hline N12 & Krom river \& Sout river (East) & 27 & 22 & 15 & 340 & 0.06 & Low \\
\hline E13 & Oorlogskloof river & Extinct & - & - & - & - & Extinct \\
\hline E14 & Muiskraal river & Extinct & $=$ & - & $\cdot$ & - & Extinct \\
\hline E15 & Renoster river & Extinct & $\cdot$ & $\cdot$ & $\cdot$ & - & Extinct \\
\hline E16 & Ongers river & Extinct & - & - & $\cdot$ & - & Extinct \\
\hline E17 & Sout river & Extinct & - & - & - & - & Extinct \\
\hline \multicolumn{2}{|c|}{ Average } & & & & & 0.11 & \\
\hline \multicolumn{2}{|c|}{ Total } & 380 & 296 & 207 & 2943 & & \\
\hline
\end{tabular}

*S = Southern Subpopulation, $\mathrm{N}=$ Northern Subpopulation, E = Extinct Subpopulation, **Sightings with duplicates removed, **-Mature individuals estimated at $70 \%$ of total sightings

An important habitat requirement for B. monticularis is alluvial soil for digging nesting burrows (Coetzee, 1994) but this soil type is the most fertile for cultivation. In the past, ploughing by Karoo farmers transformed $\sim 60 \%$ of the original habitat and remaining patches were intensively grazed by livestock (Duthie, 1989). Current threats to the species include continued habitat loss and degradation, in addition to hunting for sport and bushmeat (Duthie \& Robinson, 1990; Fabricius, 1993; Coetzee, 1994), while climate change is reducing options for habitat restoration and conservation (Hughes et al., 2008). Ours differs from previous work (Hughes et al., 2008) in providing an improved assessment of the current B. monticularis species status and red list status using species distribution modelling (SDM), a technique that has been found effective for improving red list assessments (Cassini, 2011; Keith et al., 2014; Syfert et al., 2014). Compared with the data used for the previous study (Hughes et al., 2008) and the initial red listing, the data set we used here is four times larger and was collected during an additional seven years of surveys that included the recently discovered southern population. The aims of our study were to (i) analyse all available survey data to refine estimates of population size, status 
and distribution range and (ii) use SDM to accurately determine both the extent of available habitat and the main constraints on the current species range. This information is needed for verifying the red list status and adapting conservation plans for this extremely rare mammal.

\section{Methods}

The study area is located in the semi-arid Karoo region of South Africa within distribution range of $B$. monticularis and is roughly bounded by the towns of Carnarvon and Williston (North), Victoria West (East), Prince Albert (South-East), and Touwsrivier (South-West) (Fig. 1). Species distribution modelling includes all sightings (Fig. 1) within bounding coordinates North-West extremity -29.5833 South; 17.2500 East and South-Eastern extremity -34.8333 South; 26.3750 East.

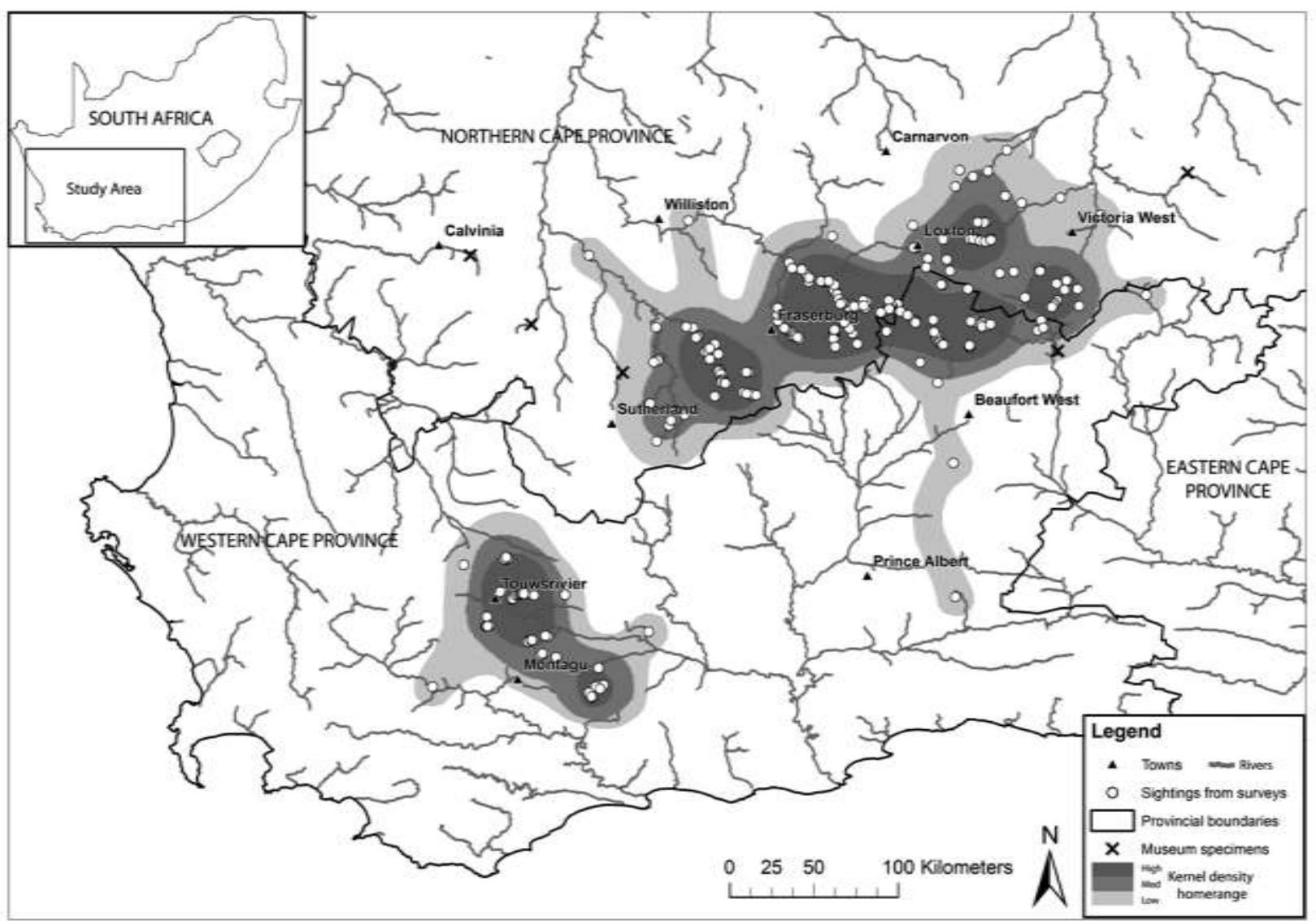

Fig 1. Study area showing the number of sightings from surveys (white circles) the location of museum specimens (black X's), kernel density estimate indicating approximate core distribution range, towns (black triangles) and provincial boundaries (black lines). The 'southern population' relates to all sightings close to the towns of Touwsrivier and Montagu enclosed in the Kernel density polygon whereas the 'northern population' refers to all sightings north and west of the southern population. 


\section{Sightings data}

Historical data exist in the form of five museum specimens collected before 1980 and an additional 20 during surveys of farms noted by Duthie (1989). All known presence data and density counts were collated from field surveys carried out from 1999-2014. Conventional sampling methods were often not feasible due to the species' elusive, nocturnal behavior and preference for dense riverine vegetation. Presence data were obtained through transect surveys, drive-counts, and sighting records by experienced biologists observing the species whilst moving either on foot or on horseback or from roadkill specimens where the identity of $B$. monticularis was confirmed through genetic testing. Most surveys were carried out by eight to fifteen people approximately $5 \mathrm{~m}$ apart, often with one to two people on horseback to increase visibility. Sightings were recorded as presence data when observed by a biologist familiar with the species or observed by at least two observers less familiar with the species. Due to B. monticularis' highly elusive nature, density count data for individual patches were only used where a minimum of eight people took part in the survey. The use of horses for surveys reduced the likelihood of repeat counts due to increased visibility of the flight path of animals flushed from cover. Surveys were conducted throughout the year from 2000 to 2010 with regularity and then less regularly since, mainly focusing on the lesser-known southern population. Surveys were primarily conducted during the day, although in areas with less dense vegetation and lower vegetation height, surveys with spotlights at night were found to be useful.

\section{Spatial analysis}

All geospatial analysis was undertaken using the Spatial Analyst extension of ArcGIS 10.2.1 (ESRI, 2013), Geospatial Modelling Environment (Beyer, 2011) and SDMtoolbox (Brown, 2014). Kernel density calculates the density of point features around each output raster cell and the kernel function used in ArcGIS 10.2 Spatial Analyst (ESRI, 2013) is based on a quadratic function (Silverman, 1986). Kernel density estimation of home range was carried out in ArcGIS with the sightings data from surveys for both northern and southern populations after data were spatially rarefied (Brown, 2014) using the following kernel grid output levels; low $-4.6 \%$ to $12 \%$, medium - $13 \%$ to $29 \%$, high $-30 \%$ to $100 \%$. The minimum cut-off point of the kernel grid from sample data (homerange) was taken as $4.6 \%$ as this represented a maximum distance of $10 \mathrm{~km}$ from sightings beyond which dispersal is unlikely for this species. Isolated points were linked to the main populations by the width of their $10 \mathrm{~km}$ buffer along closely associated rivers (Fig. 1).

Environmental biases are often introduced into species distribution models from spatially autocorrelated occurrence points resulting from sampling bias (Brown, 2014). This was addressed by first spatially rarefying the sample data using SDMtoolbox to reduce any sampling bias within the data due to more surveys possibly being conducted in easier-toaccess areas and to remove any duplicate records or multi-year repeat counts of the same individuals. The Euclidian distance specified for the spatial rarefying of the sample data was $400 \mathrm{~m}$ as this was the average distance between individuals where homerange studies were carried out (Duthie, 1989). The cut-off point for the kernel density smoothing of 
sightings data was a maximum of $10 \mathrm{~km}$ from each sighting, assumed to be beyond the maximum dispersal distance for this species based on knowledge of homerange size.

The extent of occurrence (EO0), also termed the species' range, was calculated by using kernel density home range estimation. Area of occupancy (A00) is defined as the area within its 'extent of occurrence' occupied by a taxon (Baillie et al., 2004). A00 was calculated by buffering all rivers and sightings by $1 \mathrm{~km}$ and using the buffered sightings points to clip the river buffer giving a total estimate of AOO. A buffer of $1 \mathrm{~km}$ was chosen as most of the larger patches of riverine vegetation do not extend more than $1 \mathrm{~km}$ from rivers, and all sightings were contained within these areas.

To estimate total population size, survey data representing confirmed sightings along rivers was used to calculate size of individual subpopulations along river systems.

Subpopulations were defined as groups of confirmed sightings along $1^{\text {st- }}, 2^{\text {nd }}$ and $3^{\text {rd }}$-order rivers that are within a maximum of $10 \mathrm{~km}$ of each other. If the groups of sightings are more than $10 \mathrm{~km}$ from each other they were not taken as being from the same subpopulation (Table 1). Due to limited information about this species' dispersal ability and the fact that known densities where homerange studies were carried out (Duthie, 1989) showed approximately one riverine rabbit for every $400 \mathrm{~m}$ of river length. Based on this understanding, $10 \mathrm{~km}$ between confirmed sightings was considered a reasonable distance to separate subpopulations. A minimum of six sightings was taken to represent a subpopulation (potentially representing up to three breeding pairs). Where fewer than six sightings occurred in isolation from survey data, these were assumed to be part of the nearest subpopulation based on connectivity along the rivers. In the absence of additional life history information it was assumed that $70 \%$ of all sightings during surveys represent mature (breeding) individuals (Birss, C., Pers. Comm., 2015).

\section{Climate and environmental data}

The complete set of nineteen climate predictor variables bio1-bio19 at 30 arc second spatial resolution (Table 3) were selected from the WorldClim database (Hijmans et al., 2005), which was used in the initial baseline model 19pv_No-Rar (Table 2). All data were projected into Albers Equal Area projection for Africa. Highly correlated climate data were then removed using ArcGIS 10.2 SDM Tools that evaluates correlation among input data and removes layers correlated at the user-specified level (Brown, 2014). Highly correlated climate variables can negatively affect the accuracy estimate of variable contributions from the Maxent model output. Removing highly correlated climate variables reduced the number of variables from nineteen to fifteen (Table 3 : bio 10, bio 11, bio 16, bio 17).

Additional predictor variables in the model included slope, soil and riparian area. The soil variable came from a broad-scale soil classification, the slope was created from a high resolution $25 \mathrm{~m}$ digital elevation model and the riparian variable was created by buffering all rivers by $500 \mathrm{~m}$ and expressed as the proportion of river buffer area within each grid cell. This buffer distance was chosen as the average homerange size for $B$. monticularis and is approximately 17 ha (20.9 ha for males and 12.9 ha for females and none of the 
Table 2 Outcome of Maxent distribution modelling scenarios for Bunolagus monticularis.

\begin{tabular}{|c|c|c|c|c|c|}
\hline Model Name & Model Description & $\begin{array}{l}\text { Presence } \\
\text { points }\end{array}$ & $\begin{array}{l}\text { Predictor } \\
\text { variables }\end{array}$ & $\begin{array}{l}\text { Training } \\
\text { AUC }\end{array}$ & $\begin{array}{l}\text { Test } \\
\text { AUC }\end{array}$ \\
\hline 19pv_no-rar & Only climate predictor variables included: 19 climate variables & 263 & 19 & 0.967 & 0.955 \\
\hline 22pv_no-rar & $\begin{array}{l}\text { All predictor variables included: } 19 \text { climate, } 3 \text { environmental } \\
\text { variables (ripa, slope and soil). Presence data spatially rarified. PSR. }\end{array}$ & 245 & 22 & 0.978 & 0.965 \\
\hline $18 \mathrm{pv}$ & $\begin{array}{l}\text { Four highly correlated climate variables removed leaving } 15 \text { climate } \\
\text { and } 3 \text { environmental variables. PSR. }\end{array}$ & 245 & 18 & 0.978 & 0.965 \\
\hline $10 \mathrm{pv}$ & $\begin{array}{l}\text { Climate variables reduced from } 15 \text { to } 7 \text {. Three environmental } \\
\text { variables (ripa, slope and soil). PSR. }\end{array}$ & 245 & 10 & 0.976 & 0.957 \\
\hline 18pv_N & $\begin{array}{l}\text { Sample data northern population, test data southern population. } 15 \\
\text { climate and } 3 \text { environmental variables (ripa, slope and soil). PSR. }\end{array}$ & $198^{*}$ & 18 & 0.980 & 0.723 \\
\hline 18pv_S & $\begin{array}{l}\text { Sample data southern population, test data northern population. } 15 \\
\text { climate and } 3 \text { environmental variables (ripa, slope and soil). PSR. }\end{array}$ & $47^{*}$ & 18 & 0.995 & 0.475 \\
\hline 17pv_no-rip & $\begin{array}{l}\text { Four highly correlated climate variables removed leaving } 15 \text { climate } \\
\text { variables. Riparian variable removed. PSR. }\end{array}$ & 245 & 17 & 0.969 & 0.953 \\
\hline 17pv_no-slo & $\begin{array}{l}\text { Four highly correlated climate variables removed leaving } 15 \text { climate } \\
\text { variables. Slope variable removed. PSR. }\end{array}$ & 245 & 17 & 0.976 & 0.961 \\
\hline 17pv_no-soi & $\begin{array}{l}\text { Four highly correlated climate variables removed leaving } 15 \text { climate } \\
\text { variables. Soil variable removed. PSR. }\end{array}$ & 245 & 17 & 0.977 & 0.965 \\
\hline
\end{tabular}

*198 presence points used from northern population only, 47 presence points from southern population used as test data. **47 presence points used from southern population only, 47 randomly selected presence points from northern population used as test data. Baseline model in italics. Model names; $\mathrm{pv}=$ predictor variables, no-rar = no spatial rarefying of presence data, $\mathrm{N}=$ Northern population, $\mathrm{S}=$ Southern population, no-rip = no riparian variable, no-slo = No slope variable, $\mathrm{No}$-soi $=$ No soil variable, $\mathrm{PSR}=$ Presence data spatially rarefied. Variable descriptions in Methods section and Table 3.

homeranges extended beyond 500 m either side of the river - (Duthie \& Robinson, 1990). All sample data fell within this river buffer area.

\section{Species distribution model}

Species distribution models (SDMs) are used to characterise the relationship between species records and the environmental and spatial characteristics of those location at which the species was observed (Franklin, 2009)(Elith \& Leathwick, 2009). SDMs have been applied to understand climate change impacts, spatial patterns of species diversity and the spread of invasive species (Phillips \& Dudik, 2008; Zengeya et al., 2013), and can identify previously unknown wildlife ranges (Pearson et al., 2007) and delineate spatial and ecological boundaries of species complexes (Chetan et al., 2014). Maxent has been shown to perform species distribution modelling well (Elith et al., 2006; Hernandez et al., 2006), with its output dependent on both on how closely data matches assumptions and on model complexity (Phillips \& Dudik, 2008). Maxent uses species presence records and a set of background records to predict potential distribution performs well for species distribution modelling (Elith et al., 2006; Hernandez et al., 2006; Merow et al., 2013). Its output depends on both on how closely data match assumptions and on model complexity 
Table 3 Predictor variable relative contributions for the Maxent model runs

\begin{tabular}{|c|c|c|c|c|c|c|c|c|c|c|}
\hline \multirow[b]{2}{*}{ Predictor variable description } & \multirow[b]{2}{*}{ Code } & \multicolumn{9}{|l|}{ Model } \\
\hline & & $\begin{array}{l}19 p v_{-} \\
\text {no-rar }\end{array}$ & $\begin{array}{l}\text { 22pv_ } \\
\text { no-rar }\end{array}$ & $18 \mathrm{pv}$ & $10 \mathrm{pv}$ & $\begin{array}{l}18 \mathrm{pv}_{-} \\
\mathrm{N}\end{array}$ & $\begin{array}{l}18 p v_{-} \\
S\end{array}$ & $\begin{array}{l}17 p v_{-} \\
\text {no-rip }\end{array}$ & $\begin{array}{l}17 p_{-} \\
\text {no-slo }\end{array}$ & $\begin{array}{l}17 \mathrm{pv}_{-} \\
\text {no-soi }\end{array}$ \\
\hline Riparian variable & ripa & - & 22.8 & 22.6 & 25.2 & 22.9 & 4.5 & - & 23.2 & 23.1 \\
\hline Slope & slope & - & 2.7 & 2.7 & 2.6 & 1.2 & 5.6 & 4.6 & - & 2.5 \\
\hline Soil Type & soil & - & 0.1 & 0.1 & 0.4 & 0 & 2.6 & 0.5 & 0.1 & - \\
\hline Annual Mean Temp & bio1 & 18.4 & 12 & 22.4 & - & 7.7 & 0.1 & 31.7 & 22.5 & 25.4 \\
\hline Mean Diurnal Range & bio2 & 0.1 & 0.3 & 0.3 & 1.4 & 0 & 16.1 & 0.5 & 0.3 & 0.7 \\
\hline Isothermality & bio3 & 2 & 0.6 & 0.6 & - & 1.7 & 0 & 2.4 & 1 & 1.2 \\
\hline Temp Seasonality & bio4 & 1.3 & 0.2 & 0.4 & - & 1.2 & 0 & 0.5 & 0.8 & 0.4 \\
\hline Max Temp of Warmest Month & bio5 & 1.5 & 1 & 0.7 & 10.2 & 0.6 & 0 & 1.1 & 0.6 & 0.4 \\
\hline Min Temp of Coldest Month & bio6 & 2.9 & 1.5 & 11.9 & 31.5 & 22.5 & 20 & 11 & 11.8 & 9.4 \\
\hline Temp Annual Range & bio7 & 0.1 & 0 & 0.2 & - & 0.1 & 0 & 0.2 & 0.2 & 0.2 \\
\hline Mean Temp of Wettest Quarter & bio8 & 1.9 & 0.9 & 1 & - & 1.5 & 7 & 1.7 & 0.9 & 0.6 \\
\hline Mean Temp of Driest Quarter & biog & 10.2 & 6.1 & 8 & - & 12.8 & 25.5 & 8.7 & 8.5 & 6.2 \\
\hline Mean Temp of Warmest Quarter & bio10 & 0 & 0 & - & - & - & - & - & - & - \\
\hline Mean Temp of Coldest Quarter & bio11 & 17.5 & 19.5 & - & - & - & - & - & - & - \\
\hline Annual Precipitation & bio12 & 0.3 & 0 & 0 & 0.8 & 13.7 & 0 & 0 & 0 & 0 \\
\hline Precipitation of Wettest Month & bio13 & 2.9 & 2 & 19.1 & 24.5 & 11.2 & 0.1 & 25.9 & 19.7 & 19.7 \\
\hline Precipitation of Driest Month & bio14 & 0.4 & 0.1 & 0.2 & 0.6 & 0.1 & 0.1 & 0.4 & 0.3 & 0.2 \\
\hline Precipitation Seasonality & bio15 & 1.7 & 0.9 & 1.2 & 2.8 & 1 & 18.4 & 1.3 & 1.4 & 1.7 \\
\hline Precipitation of Wettest Quarter & bio16 & 25.8 & 23.5 & - & - & - & - & - & - & - \\
\hline Precipitation of Driest Quarter & bio17 & 3.3 & 2.6 & - & - & - & - & - & - & - \\
\hline Precipitation of Warmest Quarter & bio18 & 9.2 & 2.5 & 7.9 & - & 18 & 0 & 8.6 & 7.9 & 7.3 \\
\hline Precipitation of Coldest Quarter & bio19 & 0.7 & 0.6 & 0.7 & - & 0.1 & 0 & 0.9 & 0.6 & 1 \\
\hline
\end{tabular}

Riparian variable - calculated as proportion of $1 \mathrm{~km}$ buffered rivers in each grid cell. Slope calculated from a $25 \mathrm{~m}$ digital elevation model and resampled to $30^{\prime}$ grid. Temperature in ${ }^{\circ} \mathrm{C}$. Precipitation in $\mathrm{mm}$. Model descriptions see Table 2.

(Phillips \& Dudik, 2008). Species distribution model runs were implemented using Maxent version 3.3.3k (Phillips et al., 2006).

Factors determining the $B$. monticularis distribution were assessed using combinations of 22 predictor variables fitted and evaluated in the Maxent models (Table 3). A number of combinations of sample data were also tested (Table 2) followed by a jackknife test to measure variable importance (Fig. 3). Background records were selected using Maxent default settings. Model evaluation was carried out using a random selection of $25 \%$ of the sample data used for testing model predictive performance for all the models, except the northern and southern population models. Performance of northern population model was tested using all 47 samples from southern population and performance of the southern model was tested using a random subset of 47 samples from the northern population. After 
excluding the test data samples, the number of sample records for model training after being spatially rarefied was 198 for the baseline model, 47 for southern population and 184 for all other models.

\section{Results}

A spatial analysis of B. monticularis presence data indicates that $70 \%$ of the known population occurs in the Nama-Karoo Biome, 24\% in the Succulent Karoo Biome and 6\% in the Fynbos Biome (Mucina L \& Rutherford, 2006). The total number of sightings across all twelve subpopulations is 320 individuals, which yields a total population estimate of 207 mature individuals (Table 1). A second method estimated total population size (not only mature individuals) by calculating the average density of sightings per area of $1 \mathrm{~km}$ river buffer for all subpopulations (Table 1) and multiplied by the total area (A00), gave a population size estimate of 224 individuals. This estimate is reduced to 157 if we assume $70 \%$ of population are mature individuals. The EO0, calculated as kernel density homerange, is $54,227 \mathrm{~km}^{2}$ (Fig. 1).

The baseline model 19pv_no_rar (test AUC 0.955) showed a good model fit using training and test data. Adding environmental variables ripa, slope and soil (model 22pv_no-rar, Test AUC 0.965) increases baseline model predictive power but there is still a potential issue of sampling bias. Reducing the number of climatic variables to seven (model 10pv, Test AUC 0.957) showed reduced predictive power. Removal of the slope variable (model 17pv_noslo, Test AUC 0.961) only marginally reduced overall accuracy of the model (Table 3.). Removal of the soil variable (model 17pv_no-soi, Test AUC 0.965) did not affect model accuracy, whereas removal of the riparian variable (model 17pv_no-rip, Test AUC 0.953) reduced model predictive power, but had less importance for the southern population model (Table 3). The northern population model (18pv_N, Test AUC 0.723) did not predict habitat suitability well across the whole species range and the southern population model (18pv_S, Test AUC 0.475) performed worse. The model with the highest predictive power was 18pv with the highest Test AUC value of 0.965 (Table 2). The jackknife test (regularized training gain) for model 18pv (Table 2) showed annual mean temperature (bio1) having highest gain when used in isolation and the riparian variable decreasing the gain most when omitted. For the optimal model 18pv, the most important predictor variables in order of performance are ripa, bio2, bio13, bio6 and bio9 (Table 3).

\section{Discussion}

A study of the habitat requirements of $B$. monticularis indicates the estimated total area of suitable habitat remaining could possibly support 1435 rabbits (Duthie 1989), although varying densities along riparian areas suggests that the actual population size may be substantially less. A number of surveys since the late-nineties have significantly improved estimates of the location and size of subpopulations. The population size of $B$. monticularis is critically low with an estimated twelve subpopulations totalling between 157-207 
mature individuals (Table 1). These subpopulations include three in the southern population and nine in the northern. All subpopulations are estimated to contain fewer than 50 mature individuals.

Several riverine areas that once harboured B. monticularis no longer do (Duthie, 1989). Five possible historical subpopulations are represented by five museum specimens collected in the past (Fig. 1) but surveys during the past 30 years do not confirm sightings in those localities. These five subpopulations are assumed extirpated. This includes three museum specimens collected in the north-western distribution range of $B$. monticularis along the Vis and Renoster rivers and their tributaries near the town of Calvinia. Disappearance of these subpopulations is likely due to significant habitat transformation along these particular rivers following extensive cultivation of the alluvial floodplains (Duthie et al., 1989).

\section{Model outputs}

Addressing bias in species distribution models is critical (Newbold, 2010). All species distribution modelling methods, including Maxent, rely on an unbiased sample through collecting a comprehensive set of presence records (with duplicates and errors removed). The baseline model showed good model fit, however it did not have highly correlated climate variables removed as well as sample data spatially rarefied in order to reduce sampling bias. Adding environmental variables ripa, slope \& soil to the baseline model increased model performance but the potential issue of sampling bias persists.

Several Maxent models often use a reduced number of bioclimatic variables. However, when bioclimatic variables were reduced to seven, the remaining set, chosen for their effect on vegetation (model 10pv) still performed relatively well, but did not improve on the model with fifteen bioclimatic variables. Slope and soil variables had little affect on model performance, indicating that these two predictor variables were not important across the entire species range, although slope did appear to be a more important variable for the southern population. Removal of the riparian variable reduced model performance, indicating that it is an important predictor variable for this species, although possibly more so for the northern population than for the southern population (Table 3). The model run with only northern population sample data $\left(18 p v_{-} \mathrm{N}\right)$ did not perform well for the entire species range. The model using only sample data from the southern population (18pv_S) performed the worst in terms of predicting suitable habitat across the entire species range. It is therefore important to use a model that combines both northern and southern population sample data for both training and test samples. The model 18pv, where four highly correlated climate variables were removed and three additional environmental variables added (ripa, soil, slope) as well as spatially rarefying the sample data, showed an $11 \%$ improvement in test AUC from the baseline model and was selected as the optimal model based on these factors.

Predictor variable importance for the best selected model 18pv (Table 3) shows the most important predictor variables in order of performance being riparian variable, annual 


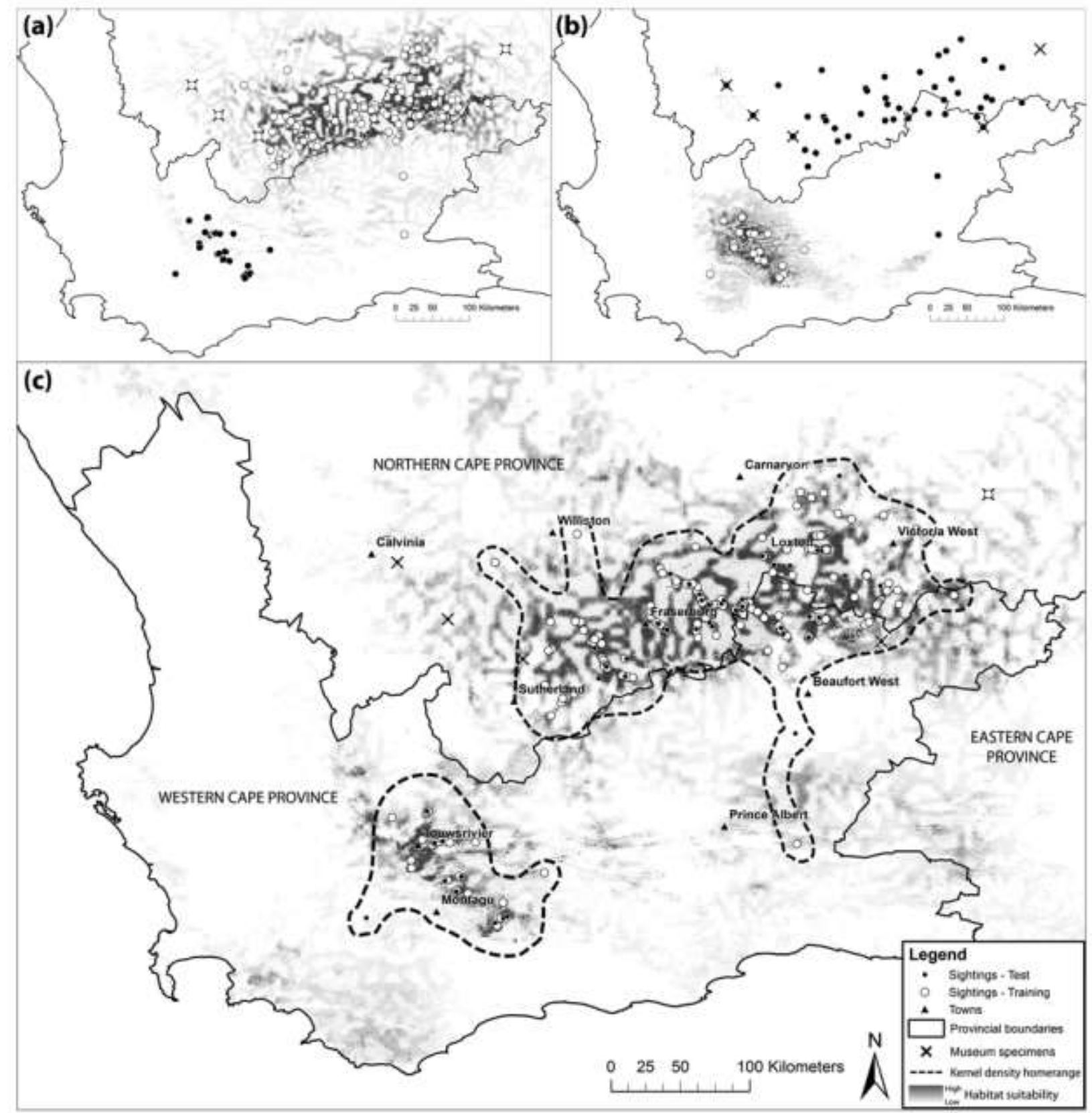

Fig 2. Habitat suitability map from Maxent models; (a) using 18pv_N northern population sample data and southern population test data, (b) 18pv_S southern population sample data and northern population test data, (c) using $18 \mathrm{pv}$ combined northern and southern population sample data and $25 \%$ random test data (Table 2). Sightings data used for training the Maxent model (white circles) and testing the Maxent model (black circles), the location of museum specimens (black X's), kernel density (dotted line) indicating approximate core distribution range, towns (black triangles) and provincial boundaries (black lines). The darker grey areas indicate better predicted conditions.

mean temperature, precipitation of the wettest month, minimum temperature of the coldest month and mean temperature of driest quarter. Interestingly for the southern and northern population models run separately, the riparian variable showed the most importance for the northern population whereas mean temperature of the driest quarter 
seemed to be the most important predictor variable for the southern population. This requires further investigation into possible evolutionary adaptive differences between the two populations. The area of unsuitable habitat separating the two populations (Fig. 2) may indicate that they may have been isolated by climatic factors for a relatively long time.

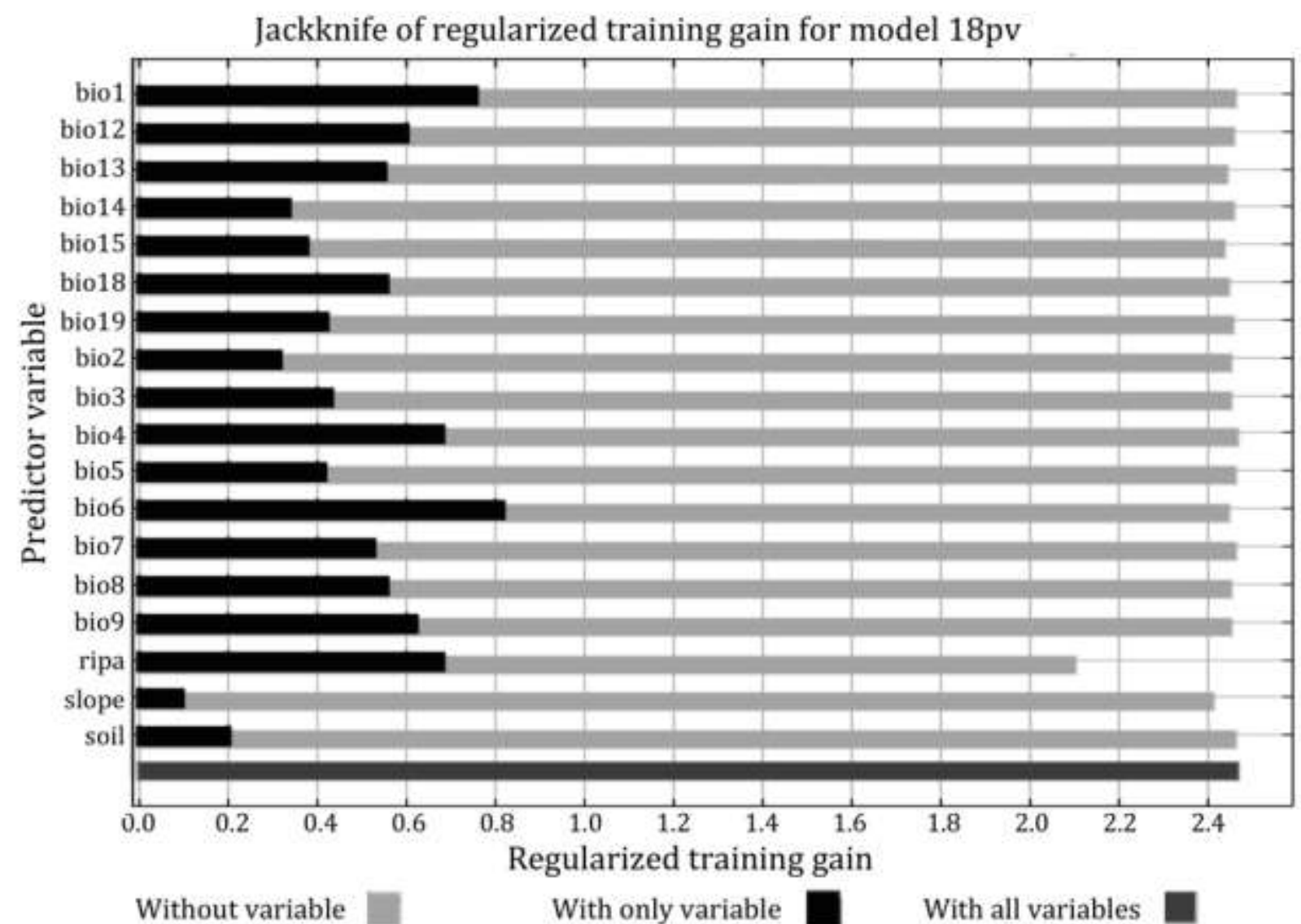

Fig 3. Jackknife test of variable importance (regularized training gain) for the Maxent model 18pv (Table 2). The predictor variable with the highest gain when used in isolation is bio 1 (Annual Mean Temperature) which appears to have the most useful information on its own. The predictor variable ripa (Riparian) decreases the gain most when omitted therefore appears to have the most information that is not present in all the other variables. Variable descriptions can be found in Table 3.

The jackknife test (regularized training gain) for variable performance showed annual mean temperature (bio1) having the most useful information on its own with the riparian variable having the most information not present in all the other variables (Fig. 3). The species distribution models in this study were run with predictor variables at a finer scale (30 arc second grid cell resolution) than previous studies (Hughes et al., 2008) allowing for the examination of finer-scale features important for environmental model predictors such as the slope and riparian variables.

These results provide a better understanding of the absolute population size and the distribution for the species, as well as the relative importance of factors that determine the 
extent of the species' range. However further analyses are required to understand the relationship between factors that may affect the northern and subpopulations in a different manner..

An initial analysis of potential climate change impacts for the northern population under the most severe General Circulation Model (GCM) suggest that, on average, over $96 \%$ of current habitat could become unsuitable due to climate change, mitigated by a possible $7 \%$ increase in range in other areas (Hughes et al., 2008). Future modelling could explore a combination of different GCM's for northern and southern populations combined, to improve our understanding of the potential impact of climate-change impact the species as well as potential future suitable habitat.

\section{Conclusion}

A population size estimate of between 157-207 mature individuals indicate an extremely low population size for B. monticularis. Together with the estimate that no subpopulation contains more than 50 mature individuals, this gives support to the species remaining listed as Critically Endangered under IUCN Red List criteria C2a(i). The best-performing model provides an improved understanding of extent of suitable habitat and which predictor variables were the most important in determining the current species range. Maxent performed well in terms of both model predictive power and accuracy and will continue to be a very useful tool for assessing potential future conservation and management actions for this species. B. monticularis can be used as both an important ecosystem health indicator species as well as an umbrella species for conservation of the unique riverine biotic communities of the Karoo region, as well as the important ecological processes that are maintained by these communities.

\section{Acknowledgements}

Funding and support provided by START Doctoral Fellowship Program, University of Pretoria, National Research Foundation, Wildlife Conservation Society, Commonwealth Scholarship Commission, Pittsburgh Zoo, Chicago Zoological Society, Endangered Wildlife Trust, GeoTerraImage and thanks to Cape Nature and Northern Cape Department of Environmental Affairs and Nature Conservation for survey data contributions.

\section{References}

AHLMANN, V., COLLINS, K. \& SEAL, U. S. (2000) Riverine Rabbit (Bunolagus monticularis): A population and habitat viability assessment workshop. Final Report., Conservation breeding specialist group (SSC/IUCN), Apple Valley, MN. 
BAILLIE, J. E. M., HILTON-TAYLOR, C. \& STUART, S. N. (eds). (2004) IUCN Red List of Threatened Species, A Global Species Assessment. Gland, Switzerland and Cambridge, UK.

BEYER, H. L. (2011) Geospatial Modelling Environment. Spatial Ecology, LLC. http://www.spatialecology.com/gme/.

BROWN, J. L. (2014) SDMtoolbox: a python-based GIS toolkit for landscape genetic, biogeographic and species distribution model analyses. Methods in Ecology and Evolution 5: 694-700.

CHETAN, N., PRAVEEN, K. K. \& VASUDEVA, G. K. (2014) Delineating ecological boundaries of Hanuman langur species complex in peninsular India using MaxEnt modeling approach. PloS one 9: e87804.

COETZEE, K. (1994) The Riverine Rabbit (Bunolagus monticularis) and its habitat: Conservation implications of an unnaturally fragmented distribution. MSc Thesis. Saasveld School of Forestry, Port Elizabeth Technikon. Port Elizabeth, South Africa.

COLLINS, K., AHLMANN, V., MATTHEE, C., TAYLOR, P., KEITH, M. \& VAN JAARSVELD, A. (2003) Bunolagus monticularis. In 2004 IUCN Red List of Threatened Species. IUCN 2004 www.redlist.org Downloaded on 17 January 2005.

DUTHIE, A. G. (1989) The Ecology of the Riverine Rabbit Bunolagus monticularis. MSc Thesis. University of Pretoria, South Africa.

DUTHIE, A. G. \& ROBINSON, T. J. (1990) The African Rabbits. In: Rabbits, Hares and Pikas: Status Survey and Conservation Action Plan. (Eds. J. A. Chapman and J. E. C. Flux). IUCN/SSC Lagomorph Specialist Group, Gland, Switzerland.

DUTHIE, A. G., SKINNER, J. D. \& ROBINSON, T. J. (1989) The distribution and status of the riverine rabbit, Bunolagus monticularis, South Africa. Biological Conservation 47: 195-202.

ELITH, J., GRAHAM, C. H., ANDERSON, R. P., DUDIK, M., FERRIER, S., GUISAN, A., HIJMANS, R. J., HUETTMANN, F., LEATHWICK, J. R., LEHMANN, A., LI, J., LOHMANN, L. G., LOISELLE, B. A., MANION, G., MORITZ, C., NAKAMURA, M., NAKAZAWA, Y., OVERTON, J. M., PETERSON, A. T., PHILLIPS, S. J., RICHARDSON, K., SCACHETTI-PEREIRA, R., SCHAPIRE, R. E., SOBERON, J., WILLIAMS, S., WISZ, M. S. \& ZIMMERMANN, N. E. (2006) Novel methods improve prediction of species' distributions from occurrence data. Ecography 29: 129-151.

ELITH, J. \& LEATHWICK, J. R. (2009) Species Distribution Models: Ecological Explanation and Prediction Across Space and Time. Annual Review of Ecology and Systematics 40: 677-697.

ESRI. (2013) ArcGIS Desktop and Spatial Analyst Extension: Release 10.2. Environmental Systems Research Institute, Redlands, CA.

FABRICIUS, C. (1993) Habitat evaluation for the riverine rabbit - a flagship species to conserve the riverine vegetation of the Karoo. Cape Nature Conservation. Internal progress report to South African Nature Foundation. Cape Town. 
FRANKLIN, J. (2009) Mapping species distributions: spatial inference and prediction. Cambridge University Press, Cambridge, UK.

HERNANDEZ, P. A., GRAHAM, C. H., MASTER, L. L. \& ALBERT, D. L. (2006) The effect of sample size and species characteristics on performance of different species distribution modeling methods. Ecography 29: 773-785.

HIJMANS, R. J., CAMERON, S. E., PARRA, J. L., JONES, P. G. \& JARVIS, A. (2005) Very high resolution interpolated climate surfaces for global land areas. International Journal of Climatology 25: 1965-1978.

HUGHES, G. O., THUILLER, W., MIDGLEY, G. F. \& COLLINS, K. (2008) Environmental change hastens the demise of the critically endangered riverine rabbit (Bunolagus monticularis). Biological Conservation 141: 23-34.

MEROW, C., SMITH, M. J. \& SILANDER, J. A. (2013) A practical guide to MaxEnt for modeling species' distributions: What it does, and why inputs and settings matter. Ecography 36: 1058-1069.

MUCINA L \& RUTHERFORD, M. C. (eds). (2006) The vegetation of South Africa, Lesotho and Swaziland. In Strelitzia 19. South African National Biodiversity Institute. Pretoria.

NEWBOLD, T. (2010) Applications and limitations of museum data for conservation and ecology, with particular attention to species distribution models. Progress in Physical Geography 34: 322.

PEARSON, R. G., RAXWORTHY, C. J., NAKAMURA, M. \& PETERSON, A. T. (2007) Predicting species distributions from small numbers of occurrence records: a test case using cryptic geckos in Madagascar. Journal Of Biogeography 34: 102-117.

PHILLIPS, S. J. \& DUDIK, M. (2008) Modeling of species distributions with Maxent: new extensions and a comprehensive evaluation. Ecography 31: 161-175.

SILVERMAN, B. W. (1986) Density Estimation Statistics and Data Analysis. Chapman and Hall, New York.

ZENGEYA, T. A., ROBERTSON, M. P., BOOTH, A. J. \& CHIMIMBA, C. T. (2013) Ecological niche modeling of the invasive potential of Nile tilapia Oreochromis niloticus in African river systems: Concerns and implications for the conservation of indigenous congenerics. Biological Invasions 15: $1507-1521$. 